\title{
Rationale and design of the Newer Versus Older Antihypertensive Agents in African Hypertensive Patients (NOAAH) trial
}

\author{
AUGUSTINE N. ODILI ${ }^{1,2}$, TOM RICHART ${ }^{1,3}$, LUTGARDE THIJS ${ }^{1}$, SAMUEL KINGUE ${ }^{4}$, \\ HILAIRE J. BOOMBHI ${ }^{4}$, DANIEL LEMOGOUM ${ }^{5}$, JOSEPH KAPTUE ${ }^{5}$, \\ MARIUS K. KAMDEM ${ }^{5}$, JEAN-BRUNO MIPINDA ${ }^{6}$, BABATUNDE A. OMOTOSO ${ }^{7}$, \\ PHILIP M. KOLO ${ }^{7}$, ADEMOLA ADERIBIGBE ${ }^{7}$, IFEOMA I. ULASI ${ }^{8}$, \\ BENEDICT C. ANISIUBA ${ }^{8}$, CHINWUBA K. IJOMA ${ }^{8}$, SERIGNE A. BA ${ }^{9}$, \\ MOUHAMADOU B. NDIAYE ${ }^{9}$, JAN A. STAESSEN ${ }^{1,3}$, JEAN-RENÉ M'BUYAMBA-KABANGU 10 \\ $\&$ ON BEHALF OF THE NOAAH INVESTIGATORS
}

\begin{abstract}
${ }^{1}$ From the Studies Coordinating Centre, Division of Hypertension and Cardiovascular Rehabilitation, Department of Cardiovascular Diseases, University of Leuven, Leuven, Belgium, ${ }^{2}$ Department of Internal Medicine, College of Health Science, University of Abuja, Abuja, Nigeria, ${ }^{3}$ Department of Epidemiology, Maastricht University, Maastricht, The Netherlands, ${ }^{4}$ Yaoundé General Hospital, Yaoundé, Cameroon, ${ }^{5}$ Douala Cardiovascular Research Institute, Douala School of Medicine, Douala, Cameroon, ${ }^{6}$ Centre Hospitalier Universitaire de Libreville, Libreville, Gabon, ${ }^{7}$ Department of Medicine, University of Ilorin Teaching Hospital, Ilorin, Nigeria, ${ }^{8}$ Department of Medicine, College of Medicine, University of Nigeria Teaching Hospital, Enugu, Nigeria, ${ }^{9}$ Centre Hospitalier National Aristide Le Dantec, Dakar, Senegal, ${ }^{10}$ Hypertension Unit, Department of Internal Medicine, University of Kinshasa Hospital, Kinshasa, Democratic Republic of Congo
\end{abstract}

\begin{abstract}
Background. Sub-Saharan Africa experiences an epidemic surge in hypertension. Studies in African Americans led to the recommendation to initiate antihypertensive treatment in Blacks with a diuretic or a low-dose fixed combination including a diuretic. We mounted the Newer versus Older Antihypertensive Agents in African Hypertensive Patients (NOAAH) trial to compare in native African patients a fixed combination of newer drugs, not involving a diuretic, with a combination of older drugs including a diuretic. Methods. Patients aged 30-69 years with uncomplicated hypertension (140-179/90-109 $\mathrm{mmHg}$ ) and two or fewer associated risk factors are eligible. After a 4-week run-in period off treatment, 180 patients will be randomized to once daily bisoprolol/hydrochlorothiazide 5/6.25 mg or amlodipine/valsartan 5/160 mg. To attain and maintain blood pressure below 140/90 $\mathrm{mmHg}$ during 6 months of follow-up, the doses of bisoprolol and amlodipine in the combination tablets will be increased to $10 \mathrm{mg}$ /day with the possible addition of $\alpha$-methyldopa or hydralazine. NOAAH is powered to demonstrate a $5-\mathrm{mmHg}$ between-group difference in sitting systolic pressure with a two-sided $p$-value of 0.01 and $90 \%$ power. NOAAH is investigator-led and complies with the Helsinki declaration. Results. Six centers in four sub-Saharan countries started patient recruitment on September 1, 2010. On December 1, 195 patients were screened, 171 were enrolled, and 51 were randomized and followed up. The trial will be completed in the third quarter of 2011. Conclusions. NOAAH (NCT01030458) is the first randomized multicenter trial of antihypertensive medications in hypertensive patients born and living in sub-Saharan Africa.
\end{abstract}

Key Words: Antihypertensive therapy, health policy and outcome research, randomized clinical trial, special populations

\section{Introduction}

Poverty, famine and infectious diseases, such as malaria and AIDS, are well-known and long-standing causes of premature death and disability in sub-Saharan Africa (1). However, this region of the world also faces an emerging epidemic of cardiovascular disease (2-4). Global trade and urbanization (5) expose developing populations to an unhealthy lifestyle, which leads to hypertension, obesity, diabetes mellitus and dyslipidemia $(2,3,5)$. Whereas hypertension virtually did

Correspondence: Jan A. Staessen, Studies Coordinating Centre, Division of Hypertension and Cardiovascular Rehabilitation, Department of Cardiovascular Diseases, University of Leuven, Campus Sint Rafaël, Kapucijnenvoer 35, Block D, Box 7001, BE-3000 Leuven, Belgium. Tel: +32 16347104 . Fax: +32 16 34 7106. E-mail: jan.staessen@med.kuleuven.be or ja.staessen@epid.unimaas.nl. 
not exist in Black Africa in the first half of the 20th century (6), currently, by 65 years of age and over, hypertension affects $30 \%$ up to $60 \%$ of African Blacks (7). This proportion is approaching the $60-70 \%$ range for African Americans of similar age (7). Lowering blood pressure and controlling hypertension is key in cardiovascular prevention.

Regarding the choice of the initial antihypertensive agent, the 2003 guidelines of the World Health Organization and the International Society of Hypertension (WHO/ISH) (8) state that for the majority of patients without a compelling indication for another class of drug, a low-dose diuretic should be considered as the first choice of therapy on the basis of comparative trial data, availability and cost. The guidelines published by the European Societies of Hypertension and Cardiology (ESH/ESC) (9) and the Joint National Committee on Prevention, Detection, Evaluation, and Treatment of High Blood Pressure (JNC7) (10) consider the initiation of antihypertensive treatment with combination therapy as an alternative to titrating, rotating and sequentially combining blood pressure lowering drugs of different classes. Using the combination of two drugs at a low dose avoids side-effects $(9,10)$ and increases adherence (11). Moreover, most patients require a combination of two or more drugs to achieve blood pressure control $(9,10)$. Combination therapy gets round the laborious and time-consuming search for an effective monotherapy, so that blood pressure targets can be reached faster (9).

\section{Rationale and design of the trial}

Several randomized clinical trials published since the WHO/ISH guidelines were issued, proved that a combination of newer antihypertensive agents, compared with older antihypertensive agents (12) or combinations including a diuretic (13) lowered blood pressure more with fewer metabolic side-effects and, more importantly, further reduced the incidence of cardiovascular complications. In line with these observations $(12,13)$ and guidelines issued by European (9) American $(10,14)$ African (15-17) and international $(8,18)$ expert committees, drug companies are now increasingly marketing fixed combinations of antihypertensive drugs. However, while sub-Saharan Africa is passing through an epidemic surge in hypertension and associated cardiovascular complications, to our knowledge, few previous trials assessed the efficacy of a combination of newer versus older antihypertensive drugs in Black hypertensive patients born and living in Africa. As a rule, findings in Black patients living in the USA or Europe are extrapolated to African Blacks. Such extrapolation does not account for differences in natural selection in previous generations (19) ethnic admixture (20), living environments and life style (21). We therefore mounted the Newer Versus Older Antihypertensive Agents in African Hypertensive Patients (NOAAH) trial (NCT01030458) to compare in Black hypertensive patients born and living in sub-Saharan Africa the blood pressure lowering efficacy of a combination of newer versus older antihypertensive agents. Patients will be randomized to 6 months of treatment with either the combination of an angiotensin II type-1 receptor blocker and a dihydropyridine calciumchannel blocker or the combination of a betablocker with a thiazide diuretic.

\section{Primary and secondary outcomes}

The primary outcome is the level of systolic blood pressure achieved on randomized treatment and measured with the patient in the seated position. Secondary outcomes are the time interval required after randomization to achieve blood pressure control defined as a level below $140 \mathrm{mmHg}$ systolic and $90 \mathrm{mmHg}$ diastolic, the incidence of adverse events (including metabolic side-effects), and the adherence to the study medication and dropout rate.

\section{Sample size}

As in previous studies the standard deviation of the changes in systolic blood pressure is around $12 \mathrm{mmHg}$, 180 randomized patients, 90 per treatment group, are required to demonstrate a $5-\mathrm{mmHg}$ between-group difference in the achieved systolic blood pressure with a two-sided $p$-value of 0.01 and $90 \%$ power.

\section{General design}

Eligible patients are treatment naïve or previously treated patients of either sex with grade- 1 or grade- 2 hypertension (9). The study starts with a screening visit, at which informed consent is obtained, followed by a run-in period with two subsequent visits at 2 -week intervals (Figure 1). To document the external validity of the NOAAH results, investigators will keep a $\log$ of the patients screened for enrollment. Patients entering the run-in period provide informed consent. Literate patients sign and date the informed consent form. Illiterate patients provide a fingerprint in the presence of an independent witness. During the run-in period, antihypertensive drug treatment is discontinued and lifestyle changes are recommended. After randomization, patients are followed up for 6 months with visits on randomized treatment scheduled after 2 and 4 weeks, and monthly thereafter until the end of the study.

\section{Selection of patients}

Eligible patients are 30-69 years old. Hypertension must be uncomplicated with a maximum of two 


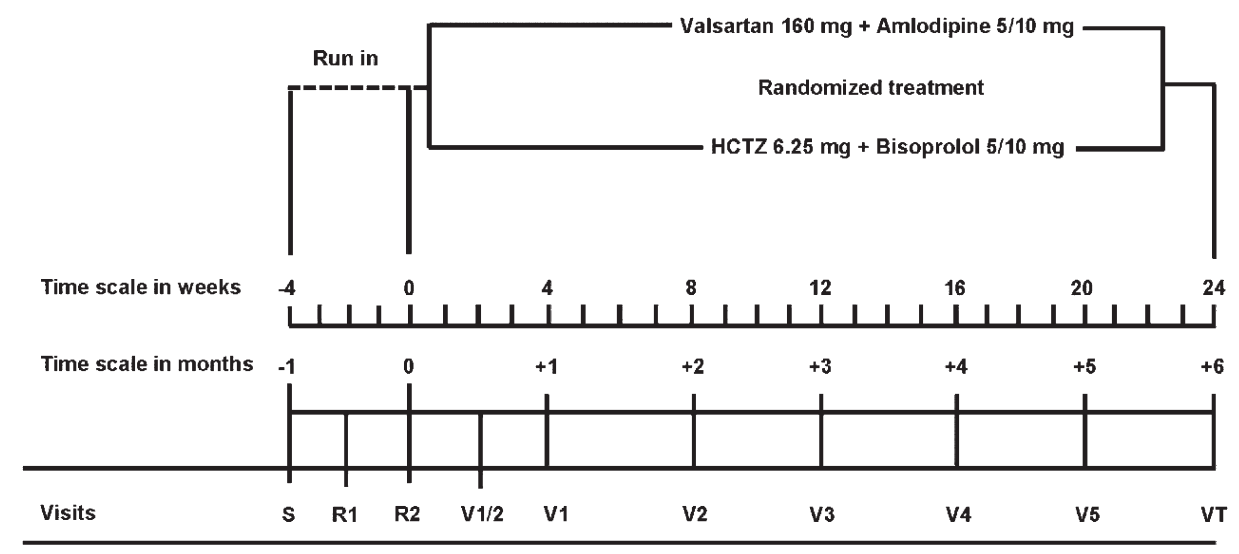

Figure 1. Schematic representation of the trial. HCTZ indicates hydrochlorothiazide.

additional risk factors, as defined in the $2007 \mathrm{ESC} /$ ESH guideline (9). The blood pressure determining eligibility is the average of three consecutive readings obtained with patients in the seated position 4 weeks after enrollment and after stopping antihypertensive drug treatment in previously treated patients. Standing systolic blood pressure, the average of three consecutive readings immediately after patients assumed the upright position, must be at least $110 \mathrm{mmHg}$. Women with childbearing potential must apply effective contraception.

The presence of three or more risk factors, a history of cardiovascular disease and diabetes mellitus (22) are exclusion criteria. Previously treated patients should not have a compelling indication, according to the ESC/ESH guideline (9), to continue antihypertensive drug treatment and should not take more than a single drug at the screening visit. Low-dose combination tablets are counted as a single drug. Atrial fibrillation is an exclusion criterion as well as electrocardiographic left ventricular hypertrophy with strain pattern or electrocardiographic left ventricular hypertrophy defined as a Sokolow-Lyon index larger than $38 \mathrm{~mm}(3.8 \mathrm{mV})$ or a Cornell voltage $\times$ duration QRS index larger than $2440 \mathrm{~mm} \times \mathrm{ms}$ (23-25). Patients with renal disorders are excluded. Renal dysfunction is a serum creatinine concentration, which is higher than $1.4 \mathrm{mg} / \mathrm{dl}$ in women or higher than $1.5 \mathrm{mg} / \mathrm{dl}$ in men (26). Proteinuria and hematuria as detected by a semi-quantitative dipstick test are also exclusion criteria. Severe non-cardiovascular disorders, psychiatric illness and substance abuse lead to exclusion.

\section{Treatment}

Treatment policies in NOAAH are in line with current guidelines $(8-10,14-16,18)$. Blood pressure must be reduced to $<140 \mathrm{mmHg}$ systolic and $<90 \mathrm{mmHg}$ diastolic. The goal blood pressure should be attained by up-titration of the randomized medication and if necessary by the combination of other antihypertensive drugs with the first-line drugs, avoiding crossover between the two arms of the study.

\section{Lifestyle}

The lifestyle measures to be recommended and reinforced during the run-in period and randomized follow-up include cessation of smoking, moderation of excessive alcohol intake, regular physical activity, weight reduction in overweight or obese patients, dietary measures to control dyslipidemia, and a moderation of salt intake.

\section{Treatment before randomization}

During the run-in period, patients should not take any blood pressure lowering drugs. Patients can continue medical treatment for non-cardiovascular diseases. The use of aspirin and lipid lowering drugs, if indicated, is encouraged, but at the discretion of the clinical investigator.

\section{Procedures at randomization}

Before the start of the trial, the Studies Coordinating Center (SCC) generated a list of treatment allocation with balanced randomization per center, using permuted blocks of four consecutive patients within each center. Before randomization, staff at SCC check all entry criteria as reported by the investigators in the case report forms (CRFs) for the screening visit $\left(V_{S}\right)$ and the two run-in visits $\left(R_{1}\right.$ and $\left.R_{2}\right)$.

\section{Treatment after randomization}

The study medication consists of the combination of $6.25 \mathrm{mg}$ hydrochlorothiazide plus $5 \mathrm{mg}$ bisoprolol to be up-titrated to $6.25 \mathrm{mg}$ hydrochlorothiazide plus $10 \mathrm{mg}$ bisoprolol $\left(\operatorname{Lodoz}^{\mathbb{R}}\right)$ in the reference group and of the combination of amlodipine $5 \mathrm{mg}$ plus valsartan $160 \mathrm{mg}$ to be up-titrated to amlodipine $10 \mathrm{mg}$ with valsartan $160 \mathrm{mg}\left(\right.$ Exforge $^{\circledR}$ ) in the experimental 
group. Patients should take the study medication in the morning. If patients experience side-effects, the randomized study medication can be continued at the lower dose or discontinued and replaced by other antihypertensive drugs. To achieve blood pressure control, the first-line study medication has to be uptitrated and combined with other antihypertensive drugs. In the two treatment groups, $\alpha$-methyldopa (Aldomet ${ }^{\circledR}$ ) up to $2 \mathrm{~g}$ per day will be used, if the blood pressure remains uncontrolled on the maximally tolerated dose of the randomized medication. Hydralazine up to $200 \mathrm{mg}$ per day is an alternative to Aldomet ${ }^{\circledR}$. Adding antihypertensive drugs should never lead to crossing the lines of randomization. In the reference group, calcium-channel blockers and blockers of the renin system (angiotensin-converting enzyme inhibitors or angiotensin II type-1 receptor blockers) cannot be used. Conversely, in the group on new drugs, beta blockers and diuretics should not be prescribed.

\section{Drug accountability}

SCC shipped Lodoz ${ }^{\circledR}$, Exforge ${ }^{\circledR}$ and Aldomet ${ }^{\circledR}$ to the recruiting clinical sites. To track the flow of medication, each box of drugs carries a unique identification number. Patients should return unused medication at the next visit. Investigators count the number of unused pills. They store used (empty) or partially used boxes of study medication for audits. Patients are classified as compliant, if they took at least $80 \%$ of the prescribed study medication and if they did not miss any dose on the days of the clinic visits. Whenever drugs are dispensed or recuperated investigators complete a drug accountability form to be forwarded to SCC along with the visit CRF.

\section{Premature discontinuation of treatment}

Doctors can prematurely withdraw patients from the trial. Valid reasons include any condition that according to the doctor's clinical judgment puts a patient at risk if the study medication is continued, the necessity to administer antihypertensive drugs that lead to crossover, uncontrolled hypertension on the maximally tolerated study medication or orthostatic hypotension. Uncontrolled hypertension is a blood pressure of at least $180 \mathrm{mmHg}$ systolic or $110 \mathrm{mmHg}$ diastolic, confirmed within 1 week after the initial measurement. Orthostatic hypotension is a drop in the systolic blood pressure upon standing by at least $40 \mathrm{mmHg}$. At any time, patients can withdraw consent or leave the trial, for instance because of symptoms or difficulties to reach the clinical sites.

\section{Measurements}

Accurate and reproducible measurements are essential for answering the research questions of NOAAH.
Table I lists the measurements to be obtained at each visit.

\section{Blood pressure}

Blood pressure will be measured by means of validated (27) oscillometric OMRON 705IT recorders (OMRON Healthcare Europe BV, Nieuwegein, The Netherlands) according to the ESC/ESH guideline (28). If, at the screening visit, the blood pressure differences between both arms are less than $10 \mathrm{mmHg}$ systolic and diastolic, all blood pressure readings throughout the trial are obtained at the non-dominant arm. Otherwise, the arm giving the highest blood pressure readings must be chosen. A standard cuff with an inflatable bladder of $22 \times 12 \mathrm{~cm}$ will be used if arm circumference is less than $32 \mathrm{~cm}$ and cuffs with a $35 \times 15 \mathrm{~cm}$ bladder on larger arms. If possible, during the whole trial, each patient's blood pressure should be measured at the same arm, using the same device and the same cuff size. A unique number identifies each OMRON recorder. For each device, investigators keep a log documenting 3 monthly checks of calibration against a mercury sphygmomanometer, defects, and other maintenance procedures, such as for instance the use of a new cuff or bladder.

\section{Electrocardiogram}

Investigators record standard 12-lead ECGs by means of the paperless Cardiax device (http://www. rdsm.eu/cardiax.html), interfaced with a computer. Using the Cardiax software, version 3.50.2 (RDSM, Hasselt, Belgium), the ECG recordings are locally printed both electronically and as a hard copy, using a PDF printer. Via the web, the ECG data are electronically delivered to SCC as an email attachment. Voltages and duration of ECG waves are derived from 16-s ECGs, while 5-min recordings are analyzed for the spectral variability of heart rate in the frequency domain.

\section{Other measurements}

A standardized questionnaire validated in previous trials $(29,30)$ will be administered to assess sideeffects. Biochemical measurements include hemoglobin, hematocrit, red and white blood cell counts, serum potassium, creatinine and total cholesterol, blood glucose, and a dipstick test on fresh urine to detect glucosuria, proteinuria and hematuria. Aliquots of serum $(2-5 \mathrm{ml})$ and urine $(5 \mathrm{ml})$ are stored at $-20^{\circ} \mathrm{C}$ or less to address unforeseen issues. Four centers perform pulse wave analysis and measure the central blood pressure and carotid-femoral pulse wave velocity by means of the SphygmoCor device and software version 7.1 (AtCor Medical Pty. Ltd., 
Table I. Measurements by visit.

\begin{tabular}{lcccccccccc}
\hline Months & -1 & $-1 / 2$ & 0 & $+1 / 2$ & +1 & +2 & +3 & +4 & +5 & +6 \\
\hline Visits & $\mathrm{S}$ & $\mathrm{R}_{1}$ & $\mathrm{R}_{2}$ & $\mathrm{~V}_{1 / 2}$ & $\mathrm{~V}_{1}$ & $\mathrm{~V}_{2}$ & $\mathrm{~V}_{3}$ & $\mathrm{~V}_{4}$ & $\mathrm{~V}_{5}$ & $\mathrm{~V}_{\mathrm{T}}$ \\
\hline Blood pressure & $\mathrm{x}$ & $\mathrm{x}$ & $\mathrm{x}$ & $\mathrm{x}$ & $\mathrm{x}$ & $\mathrm{x}$ & $\mathrm{x}$ & $\mathrm{x}$ & $\mathrm{x}$ & $\mathrm{x}$ \\
Tablet count & & & $\mathrm{x}$ & $\mathrm{x}$ & $\mathrm{x}$ & $\mathrm{x}$ & $\mathrm{x}$ & $\mathrm{x}$ & $\mathrm{x}$ & $\mathrm{x}$ \\
Blood sample & & $\mathrm{x}$ & & & $\mathrm{x}$ & & & & $\mathrm{x}$ \\
Fresh urine & & $\mathrm{x}$ & & & $\mathrm{x}$ & & & & $\mathrm{x}$ \\
$\quad$ sample & & & & & & & & & \\
Questionnaire & & $\mathrm{x}$ & & & $\mathrm{x}$ & & $\mathrm{x}$ & & $\mathrm{x}$ \\
Fundoscopy & & $\mathrm{x}$ & & & & & & & $\mathrm{x}$ \\
ECG & $\mathrm{x}$ & & & $\mathrm{x}$ & & $\mathrm{x}$ & & $\mathrm{x}$ \\
PWA and PWV & $\mathrm{x}$ & & & $\mathrm{x}$ & & $\mathrm{x}$ & & $\mathrm{x}$ \\
\hline
\end{tabular}

ECG indicates electrocardiogram. PWA and PWV indicate and measurement of pulse wave velocity by means of the SphygmoCor device and software at four centers.

West Ryde, New South Wales, Australia), as previously described (31).

\section{Management}

NOAAH is an investigator-initiated and investigatorled randomized clinical trial, partially supported by Novartis. NOAAH involves seven clinical sites, all located in sub-Saharan Africa, the Hypertension Unit at the University of Kinshasa as sponsor and the Division of Hypertension and Cardiovascular Rehabilitation at the University of Leuven as coordinating center.

\section{Ethics}

NOAAH fully complies with the guidelines for good clinical practice outlined in the Helsinki declaration (32), as well as with all international, European and national regulations. Each participating center received approval from the local Institutional Review Board and, if applicable, from National Regulatory Authorities. The sponsor obtained ethical approval from the Ethics Committee of the Faculty of Medicine, University of Kinshasa, Democratic Republic of Congo.

\section{Role of the sponsor}

The Hypertension Unit at the University of Kinshasa will be responsible for the organization and execution of site visits to the clinical centers.

\section{Role of the coordinating office}

SCC in Leuven is responsible for the overall coordination of the trial and for quality control and assurance. SCC will construct and maintain the NOAAH database, run the statistical analysis, and in collaboration with the clinical sites and the sponsor publish the NOAAH reports. During the trial, investigators will remain blinded to the results of the trial. This does not preclude publication of progress reports on recruitment and baseline characteristics.

\section{Flow of data}

SCC developed the CRFs as interactive PDF forms, which investigators complete at the clinical sites and print for the local patient files. XML files exported from the PDFs are sent to SCC as email attachments. After quality control and addition of the codes for symptoms, diseases and concurrent medications at SCC, the XML files are directly imported into the SAS database, using the SAS XML Mapper, version 9.2. Conversely, PDFs generated from the received XML files at SCC can be returned to the clinical sites, if questions arise or issues need conformation. This setup makes immediate exchange of information possible and avoids data entry at SCC. Each clinical site maintains a local database of PDF and XML files ordered by visit and type of information. The flow of information as organized in NOAAH does not require continuous access to Internet and allows for power cuts, which might occur in some sub-Saharan countries. It also avoids double data entry at SCC and enables short turnaround times in the exchange of information between the clinical sites and SCC, which proved to be essential to guarantee quality and to standardize the collection of information.

\section{Statistical analysis}

For database management and statistical analysis SAS software, version 9.2 (SAS Institute Inc., Cary, NC, USA) is used. The software was validated according to the 21 Code of Federal Regulations (http://www.fda.gov/cder/offices/ods/ regs.htm). The primary and secondary hypotheses related to blood pressure will be assessed in two cohorts of patients. The intention-to-treat analysis includes all patients who have at least one evaluation available after randomization. In case of missing data, the last observation will be carried forward. The per-protocol analysis involves all patients, who fulfilled the eligibility criteria, took at least $80 \%$ of the prescribed study medication, did not take any drugs prohibited by the protocol, and underwent a complete evaluation at the end of follow-up. Adverse events and dropouts will be assessed in all randomized patients, who took at least one dose of the study medication. All statistical tests will be two-sided.

The primary and secondary endpoints measured on a continuous scale will be analyzed by repeatedmeasures analysis of variance. The secondary analysis will also include binary blood pressure endpoints, which will be analyzed by means of McNemar's test. Responders have a decrease in their sitting systolic 
blood pressure on randomized treatment by at least $10 \%$. Controlled patients maintain a blood pressure level below $140 \mathrm{mmHg}$ systolic and $90 \mathrm{mmHg}$ diastolic. Time to blood pressure control will be evaluated using Kaplan-Meier estimates, the log-rank test and Cox regression. To determine the profile of controlled patients or responders, the continuous and binary blood pressure endpoints will be subjected to multiple (stepwise) linear and logistic regressions.

While accounting for concurrent medications, the safety and tolerability analysis will involve clinical signs and symptoms, adverse events, laboratory tests on blood and urine, and the ECG measurements. Adverse events will be coded using the ICD code, version 10 (http:/www.who.int/classifications/apps/ icd/icd10online) and concomitant medications according to the coding system applied in the Flemish Study on Genes, Environment and Health Outcomes $(33,34)$ and in the European Project on Genes in Hypertension (35). After conversion to SI units, the biochemical measurements will be normalized to a unique reference range (36). To facilitate identification of outliers, normalized values at baseline and follow-up will be plotted against each other.

\section{Time line}

The first NOAAH investigators' meeting took place in Paris, France, on December 18, 2008 with a second meeting in Abuja, Nigeria, on September 26, 2009. A training workshop was organized in Doula, Cameroon, on August 26-27, 2010. It took almost 2 years to obtain the required approvals, to mount the required infrastructure and to train the clinical investigators. Patient recruitment started on September 1, 2010. On December 1, 195 patients had been screened, 171 had been enrolled and 51 were randomized and followed up (Figure 2). The study should be completed by the third quarter of 2011 and submitted for publication by the end of that year.

\section{Discussion}

To our knowledge, NOAAH is the first randomized multicenter clinical trial on antihypertensive therapies that is exclusively running in sub-Saharan Africa. The underlying hypothesis is that in Blacks born and living in Africa the combination of newer agents will be more effective in blood pressure lowering and in achieving blood pressure control with fewer sideeffects than the combination of older drugs. If these assumptions hold true, they challenge the current recommendation of the WHO/ISH (8) to start antihypertensive treatment with diuretics in Black hypertensive patients, in particular because lowering systolic blood pressure (37-40) and early blood pressure control $(12,41)$ are essential for the prevention of cardiovascular complications. Although according

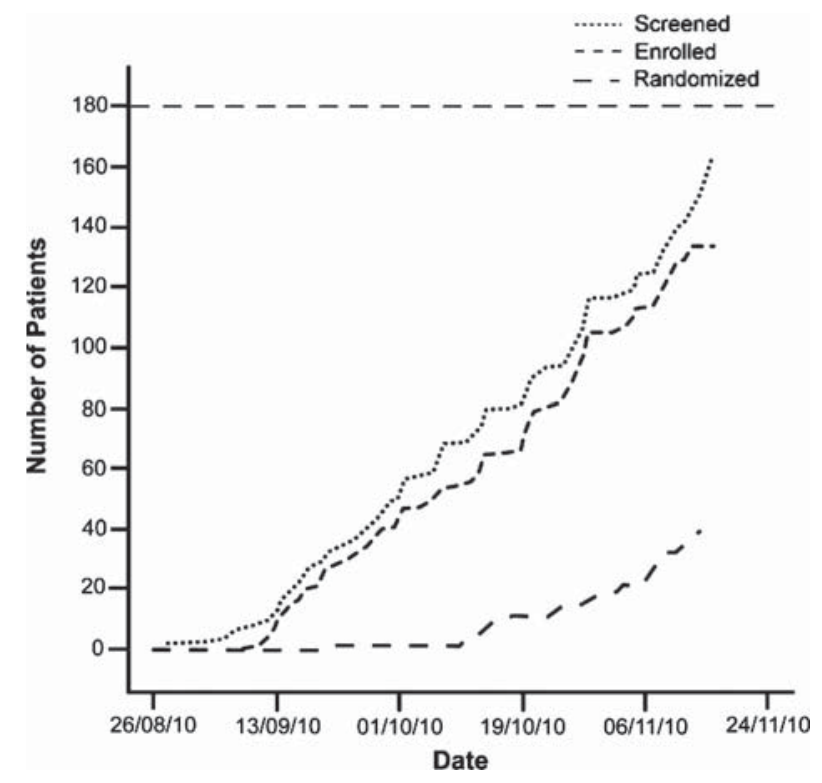

Figure 2. Number of patients screened, enrolled and randomized on December 1, 2010. The dotted line indicates the number of patients to be randomized.

to our hypothesis newer drugs will be more effective than older agents, all statistical tests will be twosided. Because blood pressure measurement is automated in NOAAH, the primary endpoint is measured free of observer bias.

NOAAH will generate information that is helpful in addressing the epidemic of cardiovascular disease in sub-Saharan Africa (42). Reliable statistics on the prevalence or incidence of cardiovascular morbidity and mortality in sub-Saharan Africa are scarce (43). Nevertheless, several hospital based studies (44-60) highlighted the contribution of hypertension to morbidity and mortality among black African patients. Hypertension-related complications were responsible for around $20 \%$ of all adult medical admissions in two reports from Nigeria $(44,45)$ and one from South Africa (46). In recently published series (47-50,59), the prevalence of hypertension among patients with heart failure ranged from $33.3 \%$ (49) to $69.6 \%$ (60). It was $77.8 \%(50)$ and $51.0 \%$ (51) among stroke patients below age 45 years and in the general population, respectively, and $49.0 \%$ and $45.6 \%$ among Ghanaian (54) and South African (55) patients with end-stage renal disease. Hypertension was a comorbidity in $51.9 \%$ patients with aortic aneurysm admitted to a tertiary referral hospital in Kenya (61). We recently assessed the frequency and determinants of in-hospital mortality among patients admitted for hypertension to two city hospitals in Mbuji Mayi, Congo (58). Among 401 consecutive patients (mean age 54.3 years; 129 women), 89 (22.2\%) died over a median follow-up of 15 days. The multivariable-adjusted probability of death increased with systolic pressure $(p=0.0013)$ on admission (58). In a Nigerian teaching hospital in Enugu, the case-fatality rate among patients admitted because of hypertension was $42.9 \%$ (56). 
By design, the NOAAH trial closely follows the ESC/ESH (9) and several African (15-17) guidelines. First, NOAAH patients have uncomplicated grade- 1 or grade- 2 hypertension with no more than two additional risk factors. Diabetes, renal dysfunction and previous cardiovascular disease are exclusion criteria. Thus, NOAAH patients have a low to moderate increased risk above the average. For such patients, the guidelines $(9,15-17)$ propose that lifestyle changes should first be recommended and reinforced for several weeks (grade 2) or even months (grade 1) before antihypertensive drug treatment is initiated. These recommendations $(9,15-17)$ explain why having a 4 -week run-in period without blood pressure lowering treatment should not raise ethical concerns. The run-in period allows us to ascertain the diagnosis of hypertension with greater certainty. Second, as recommended by most current guidelines $(8-10,14-18)$, combination therapy is used to initiate antihypertensive treatment in NOAAH patients. The advantages of combination therapy are: tighter and earlier blood pressure control than monotherapy or sequential combination therapy, respectively; simplification of the therapeutic regimen and therefore better adherence; avoidance of dose-dependent adverse effects experienced with higher doses of single agents; and attenuation of the adverse effects of some agents when used alone. Third, Blacks have a higher sensitivity to salt intake and an impaired ability to excrete ingested salt. This leads to an overall expansion of intravascular volume. According to the ABCD algorithm $(62,63)$, both treatment arms of NOAAH include a drug class that addresses the low-renin volume component of hypertension (hydrochlorothiazide and amlodipine) as well as agents (bisoprolol and valsartan) interfering with the high-renin vasoconstrictor component (63). Diuretics and calciumchannel blockers potentiate the efficacy of renin system inhibitors in Black low-renin patients (64).

The lower-dose reference medication in NOAAH is the combination of bisoprolol $5 \mathrm{mg}$ plus $6.25 \mathrm{mg}$ hydrochlorothiazide. Given once daily, this combination lowers blood pressure throughout $24 \mathrm{~h}(65,66)$ and significantly more than bisoprolol $5 \mathrm{mg} /$ day or hydrochlorothiazide $25 \mathrm{mg}$ /day given as single components (66). A double-blind parallel group doseescalation trial involved 539 patients with uncomplicated mild-to-moderate hypertension, who were randomized to the combination of bisoprolol plus hydrochlorothiazide $(2.5 / 6.25,5 / 6.25$ and $10 / 6.25 \mathrm{mg}$ /day, enalapril $(5,10,20 \mathrm{mg} /$ day $)$ or amlodipine $(2.5,5$, $10 \mathrm{mg} /$ day) for a period of 12 weeks. The combination was at least as effective as amlodipine and more effective than enalapril in both women and men (67). Findings were similar in a combined analysis (68) of two studies $(69,70)$, in which, after stratification for ethnicity, 114 Blacks and 427 non-Blacks were randomized and followed up for 12 weeks. In Blacks, the combination of bisoprolol plus hydrochlorothiazide resulted in significantly greater reductions of systolic and diastolic blood pressure than enalapril or placebo, but was not significantly different from amlodipine (68). In non-Blacks, the combination produced greater reductions in diastolic blood pressure than amlodipine or enalapril (68). The placebo-corrected decreases in blood pressure and the control rates were similar in Blacks and non-Blacks. In both ethnicities, the discontinuation rate related to uncontrolled blood pressure or adverse events was lowest on the combination (68).

Experimental treatment in NOAAH consists of the combination of amlodipine plus valsartan. One report based on two randomized, double-blind, placebo-controlled, trials addressed the blood pressure lowering efficacy of several combinations of these components (71). Both studies consisted of a 2-week washout period, which was followed by a singleblind, placebo run-in period of 2-4 weeks, and thereafter by an 8-week, double-blind, active-treatment period. In the first study, the daily doses were 2.5 to $5 \mathrm{mg}$ for amlodipine and 40, 80, 160 or $320 \mathrm{mg}$ for valsartan; in the second study, they were $10 \mathrm{mg}$ for amlodipine and 160 or $320 \mathrm{mg}$ for valsartan. In 2478 patients, the blood pressure reductions were larger with the combinations than with the corresponding monotherapy components with a positive doseresponse for all combinations (Table II) (71). In 3155 patients analyzed for safety, the overall rate of adverse effects on combination therapy $(44.5 \%)$ was similar on amlodipine $(45.7 \%)$, but larger than on valsartan monotherapy (39.8\%). Peripheral edema occurred less on the combination $(5.4 \%)$ than on amlodipine given alone (8.7\%), but more frequently than on valsartan monotherapy $(2.1 \%)$ or placebo $(3.0 \%)$. The corresponding rates of headache were $4.3 \%, 7.6 \%, 4.8 \%$ and $5.9 \%$, respectively (71). The rate of adverse events leading to discontinuation of the treatment was low on combination therapy $(1.8 \%)$ and comparable with that on placebo $(2.1 \%)$. Angiotensin II receptor blockers dilate postcapillary vessels and therefore reduce the transmural pressure in the capillary bed, which is increased on monotherapy by dihydropyridines by precapillary vasodilatation. This explains the reduction of ankle edema on combination therapy $(72,73)$. Other trials comparing the combination of amlodipine plus valsartan in Black $(74)$ or predominantlyWhite $(75,76)$ patients were confirmatory.

Clinical research in developing countries differs in several ways from that in developed countries, partly because of the cultural differences, relatively poor health care and research infrastructure, wide socioeconomic divide within the society, illiteracy of patients, and lack of sufficient numbers of trained investigators and support personnel in these countries (77). For these reasons, we did not implement self-measurement of blood pressure at home. We also organized three investigators' meetings to overcome 
Table II. Average systolic/diastolic blood pressure reductions ( $\mathrm{mmHg}$ ) by 8 -week once-daily treatment with different daily doses (mg) of amlodipine and valsartan given alone or in combination.

\begin{tabular}{|c|c|c|c|c|c|}
\hline \multicolumn{4}{|c|}{ Study 1} & \multicolumn{2}{|c|}{ Study 2} \\
\hline Daily dose amlodipine & 0 & 2.5 & 5 & 0 & 10 \\
\hline \multicolumn{6}{|l|}{ Daily dose valsartan } \\
\hline 0 & $7.3 / 7.1$ & $12.4 / 9.3$ & $15.1 / 11.5$ & $12.9 / 8.6$ & $24.1 / 15.6$ \\
\hline 40 & $11.8 / 10.1$ & $15.5^{\mathrm{ab} / 10.8}$ & $19.6 /{ }^{\mathrm{ab}} 14.6^{\mathrm{ab}}$ & $\ldots$ & $\ldots$ \\
\hline 80 & $12.9 / 9.7$ & $17.0^{\mathrm{ab} / 13.4^{\mathrm{ab}}}$ & $20.8{ }^{\mathrm{ab}} 14.5^{\mathrm{ab}}$ & $\ldots$ & $\ldots$ \\
\hline 160 & $15.1 / 11.0$ & $16.7^{\mathrm{b} / 13.3^{\mathrm{ab}}}$ & $19.5 / \mathrm{ab}^{\mathrm{ab}} 14.2^{\mathrm{ab}}$ & $20.2 / 13.3^{\mathrm{a}}$ & $27.8^{\mathrm{ab} / 17.6^{\mathrm{ab}}}$ \\
\hline 320 & $15.7 / 13.4$ & $18.3^{\mathrm{b} / 14} .2^{\mathrm{b}}$ & $22.7^{\mathrm{ab} / 15.9^{\mathrm{ab}}}$ & $19.8 / 13.3^{a}$ & $28.4^{\mathrm{ab}} / 18.6^{\mathrm{ab}}$ \\
\hline
\end{tabular}

All differences with placebo ( $0 \mathrm{mg} /$ day) were statistically significant. ${ }^{\mathrm{a}} p<0.05$ versus the same daily dose of valsartan monotherapy; ${ }^{\mathrm{b}} p<0.05$ versus the same daily dose of amlodipine monotherapy. Adapted with permission from Philipp et al. (80).

these difficulties and to familiarize the clinical researchers with all aspects of the trial. By design, $\mathrm{NOAAH}$ is a simple trial, in which intentionally the number of biochemical measurements is limited to those required to assess safety. All data traffic between the clinical sites and SCC is organized as email attachment. This setup does not require constant Internet access and allows immediate quality control and feedback on receipt of data. ECGs are recorded using a paperless device not requiring consumables and software that allows analysis of heart rate variability in the frequency domain (78). Four centers participate in pulse wave analysis and measurement of pulse wave velocity. In this ancillary study, we will assess the influence of older versus newer drugs on the central blood pressure and arterial stiffness and investigate whether we can reproduce findings in White hypertensive patients (79). Thus, although simple in design, NOAAH is poised to move knowledge forward. The trial is only running in countries, in which the randomized medications are marketed and available to patients after they left the trial.

In conclusion, current guidelines strongly support the use of combination therapy as first-line treatment in hypertensive patients. However, to our knowledge, there is presently little information on blood pressure lowering efficacy and rate of adverse events on fixed combinations consisting of older versus newer drugs in Black hypertensive patients born and living in sub-Saharan Africa. NOAAH will generate this information by the end of 2011. On March 1, 2011, 237 patients had been enrolled in the run-in period and over 136 had been randomized.

\section{Acknowledgment}

The Belgian Hypertension Committee endorsed the NOAAH trial. Prof. M. O'Rourke (Saint Vincent's Clinic, University of New South Wales, Sidney, Australia) helped in raising support for the ancillary substudy on arterial stiffness. The authors gratefully acknowledge the expert clerical and secretarial support of Ms. Sandra Covens, Ms. Ya Zhu and Ms. Barbara Andries.

Registration number: NCT01030458

\section{Role of the funding source}

Novartis provided unrestricted financial support and the Exforge study medication. The funding source had no role in the design of the trial, data collection, database management, statistical analysis or writing of the report. The sponsor (J.R. M'BuyambaKabangu) and the scientific coordinator (J.A. Staessen) had full access to all of the data and accept the final responsibility for the decision to submit this manuscript for publication. Novartis was permitted to review the manuscript and suggest changes, but the authors retained the final decision on the content of this article.

\section{Conflict of interest}

None of the authors declares a conflict of interest with regard to the information presented in this manuscript.

\section{References}

1. Murray CJL, Lopez AD. Mortality by cause for eight regions of the world: global burden of disease study. Lancet. 1997; 349:1269-1276.

2. Reddy KS, Yusuf S. Emerging epidemic of cardiovascular disease in developing countries. Circulation. 1998;97:596-601.

3. Bonita R, Reddy S, Galbraith S, Bettcher D, MacIntyre M, Peden $M$, et al. Neglected global epidemics: Three growing threats. In Beaglehole R, Irwin A, Prentice T, editors. The World Health Report 2003 - Shaping the Future. Geneva: World Health Organization; 2003. p 83-102.

4. Perkovic V, Huxley R, Wu Y, Prabhakaran PD, MacMahon S. The burden of blood pressure-related disease: A neglected priority in global health. Hypertension. 2007;50:991-997.

5. Sobngwi E, Mbanya JC, Unwin NC, Porcher R, Kengne AP, Fezeu L, et al. Exposure over the life course to an urban environment and its relation with obesity, diabetes, and hypertension in rural and urban Cameroon. Intern J Epidemiol. 2004;33:769-776.

6. Donnison C. Blood pressure in African natives: Its bearing on the aetiology of hyperpiesa and arteriosclerosis. Lancet. 1929;i:6-7.

7. Opie LH, Seedat YK. Hypertension in sub-Saharan African populations. Circulation. 2005;112:3562-3568.

8. World Health Organization ISoHWG. 2003 World Health Organization (WHO)/International Society of Hypertension (ISH) statement on management of hypertension. J Hypertens. 2003;21:1983-1992. 
9. Mancia G, De Backer G, Dominiczak A, Cifkova R, Fagard R, Germano G, et al. 2007 guidelines for the management of arterial hypertension. The task force for the management of arterial hypertension of the European Society of Hypertension (ESH) and of the European Society of Cardiology (ESC). J Hypertens. 2007;25:1105-1187.

10. Chobanian AV, Bakris GL, Black BK, Cushman WC, Green LA, Izzo JL, Jr., et al., and the National High Blood Pressure Education Program Coordinating Committee. Seventh report of the Joint National Committee on Prevention, Detection, Evaluation, and Treatment of High Blood Pressure. Hypertension. 2003;42:1206-1252.

11. Chapman RH, Benner JS, Petrilla AA, Tierce JC, Collins SR, Battleman DS, et al. Predictors of adherence with antihypertensive and lipid-lowering therapy. Arch Intern Med. 2005; 165:1147-1152.

12. Dahlöf B, Sever PS, Poulter NR, Wedel H, Beevers DG, Caulfield $\mathrm{M}$, et al., for the ASCOT Investigators. Prevention of cardiovascular events with an amlodipine \pm perindopril strategy compared with an atenolol \pm thiazide strategy. The Anglo-Scandinavian Cardiac Outcomes Trial - Blood Pressure Lowering Arm (ASCOT-BPLA): A multicentre randomised controlled trial. Lancet. 2005;366:895-906.

13. Jamerson K, Weber MA, Bakris GL, Dahlöf B, Pitt B, Shi V, et al., for the ACCOMPLISH trial investigators. Benazapril plus amlodipine or hydrochlorothiazide for hypertension in high-risk patients. N Engl J Med. 2008;359:2417-2428.

14. Consensus Statement of the Hypertension in African Americans Working Group of the International Society on Hypertension in Blacks. Management of high blood pressure in African Americans. Arch Intern Med. 2003;163:525-541.

15. Joint National Hypertension Guideline Working Group 2006, Seedat YK, Croasdale MA, Milne FJ, Opie LH, PinkneyAtkinson VJ, Rayner BL. South African Hypertension Guideline 2006. S Afr Med J. 2006;96:337-362.

16. Lemogoum D, Seedat YK, Mabadeje AFB, Mendis S, Bovet P, Onwubere B, Blacket KN, Lenfant C, M'BuyambaKabangu JR, Block P, Belhocine P, Degaute JP, on behalf of the International Forum for Hypertension control and prevention in Africa (IFHA). Recommendations for prevention, diagnosis and management of hypertension and cardiovascular risk factors in sub-Saharan Africa. J Hypertens. 2003; 21:1993-2000.

17. Guidelines Committee. Guidelines for the Management of Hypertension in Nigeria. Enugu, Nigeria, Ezu Books Ltd; 2005.

18. Flack JM, Sica DA, Bakris G, Brown AL, Ferdinand KC, Grimm RH, Jr., et al., on behalf of the International Society on Hypertension in Blacks. Management of hypertension in Blacks: An update of the International Society of Hypertension in Blacks Consensus Statement. Hypertension. 2010; 56:780-800

19. Young JH, Chang YP, Kim JDO, Chretien JP, Klag MJ, Levine AS, et al. Differential susceptibility to hypertension is due to selection during the out-of Africa expansion. PLoS Genet. 2005;1:e82.

20. Zhu X, Luke A, Cooper RS, Quertermous T, Hanis C, MosleyT, et al. Admixture mapping for hypertension loci with genome-wide markers. Nat Genet. 2005;37:177-181.

21. Kaufman JS, Owoaje EE, James SA, Rotimi CN, Cooper RS. Determinants of hypertension in West Africa: Contribution of anthropometric and dietary factors to urban and socioeconomic gradients. Am J Epidemiol. 1996;143:1203-1218.

22. The Expert Committee on the Diagnosis and Classification of Diabetes Mellitus. Report of the Expert Committee on the Diagnosis and Classification of Diabetes Mellitus. Diabet Care. 1999;22 Suppl 1:S5-S19.

23. Sokolow M, Lyon TP. The ventricular complex in left ventricular hypertrophy as obtained by unipolar precordial and limb leads. Am Heart J. 1949;37:161-186.

24. Casale PN, Devereux RB, Alonso DR, Campo E, Kligfield P. Improved sex-specific criteria of left ventricular hypertrophy for clinical and computer interpretation of electrocardiograms: Validation with autopsy findings. Circulation. 1987; 75:565-572

25. Okin PM, Roman MJ, Devereux RB, Kligfield P. Electrocardiographic identification of increased left ventricular mass by simple voltage-duration products. J Am Coll Cardiol. 1995;24:417-423

26. The Task Force for the Management of Arterial Hypertension of the European Society of Hypertension (ESH) and of the European Society of Cardiology (ESC), Mancia G, De Backer G, Dominiczak A, Cifkova R, Fagard R, Germano G, et al. 2007 guidelines for the management of arterial hypertension. Eur Heart J. 2007;28:1462-1536.

27. El Assaad MA, Topouchian JA, Asmar RG. Evaluation of two devices for self-measurement of blood pressure according to the international protocol: The Omron M5-I and the Omron 705IT. Blood Press Monit. 2003;8:127-133.

28. O’Brien E, Asmar R, Beilin L, Imai Y, Mancia G, Mengden $T$, et al., on behalf of the European Society of Hypertension Working Group on Blood Pressure Monitoring. Practice guidelines of the European Society of Hypertension for clinic, ambulatory and self blood pressure measurement. J Hypertens. 2005;23:697-701.

29. Staessen JA, Byttebier G, Buntinx F, Celis H, O'Brien ET, Fagard R, for the Ambulatory Blood Pressure Monitoring and Treatment of Hypertension Investigators. Antihypertensive treatment based on conventional or ambulatory blood pressure measurement. A randomized controlled trial. JAMA. 1997;278:1065-1072.

30. Staessen JA, Den Hond E, Celis H, Fagard R, Keary L, Vandenhoven G, et al., for the Treatment of Hypertension Based on Home or Office Blood Pressure (THOP) Trial Investigators. Antihypertensive treatment based on blood pressure measurement at home or in the physician's office. A randomized controlled trial. JAMA. 2004;291:955-964.

31. Shiburi CP, Staessen JA, Maseko M, Wojciechowska W, Thijs L, Van Bortel LM, et al. Reference values for SphygmoCor measurements in South Africans of African ancestry. Am J Hypertens. 2006;19:40-46.

32. 41 st World Medical Assembly. Declaration of Helsinki: Recommendations guiding physicians in biomedical research involving human subjects. Bull Pan Am Health Organ. 1990;24:606-609.

33. Staessen JA, Kuznetsova T, Zhang H, Maillard M, Bochud M, Hasenkamp $S$, et al. Blood pressure and renal sodium handling in relation to genetic variation in the DRD1 promoter and GRK4. Hypertension. 2008;51:1643-1650.

34. Li Y, Zagato L, Kuznetsova T, Tripodi G, Zerbini G, Richart $\mathrm{T}$, et al. Angiotensin-converting enzyme $\mathrm{I} / \mathrm{D}$ and $\alpha$-adducin Gly460Trp polymorphisms. From angiotensinconverting enzyme activity to cardiovascular outcome. Hypertension. 2007;49:1291-1297.

35. Kuznetsova T, Staessen JA, Brand E, Cwynar M, Stolarz K, Thijs L, et al. Context-dependency of relations between cardiovascular phenotypes and genes involved in sodium homeostasis: Findings from the European Project on Genes in Hypertension. Curr Hypertens Rev. 2006;2:275-281.

36. Chuang-Stein C. Some issues concerning the normalization of laboratory data based on reference ranges. Drug Inform J. 2000;35:153-156

37. Staessen JA, Wang JG, Thijs L. Cardiovascular prevention and blood pressure reduction: A meta-analysis [erratum published in The Lancet 2002, volume 359, January 26, p 360]. Lancet. 2001;358:1305-1315.

38. Blood Pressure Lowering Treatment Trialists' Collaboration. Effects of different blood-pressure-lowering regimens on major cardiovascular events: Results of prospectivelydesigned overviews of randomised trials. Lancet. 2003;362: 1527-1535.

39. Staessen JA, Li Y, Thijs L, Wang JG. Blood pressure reduction and cardiovascular prevention: An update including the 
2003-2004 secondary prevention trials. Hypertens Res. 2005; 28:385-407.

40. Verdecchia P, Reboldi G, Angeli A, Gattobigio R, Bentivoglio $M$, Thijs $L$, et al. Angiotensin-converting enzyme inhibitors and calcium channel blockers for coronary heart disease and stroke prevention. Hypertension. 2005;46:386-392.

41. Staessen JA, Thijs L, Fagard R, Celis H, Birkenhäger WH, Bulpitt CJ, et al., for the Systolic Hypertension in Europe (SystEur) Trial Investigators. Effects of immediate versus delayed antihypertensive therapy on outcome in the Systolic Hypertension in Europe Trial. J Hypertens. 2004;22:847-857.

42. Cooper RS, Rotimi CN, Kaufman JS, Muna WFT, Mensah GA. Hypertension treatment and control in sub-Saharan Africa: The epidemiological basis for policy. Br Med J. 1998;316:614-617.

43. Cooper RS, Osotimehin B, Kaufman JS, Forrester T. Disease burden in sub-Saharan Africa: What should we conclude in the absence of data? Lancet. 1998;351:208-210.

44. Ukoh VA. Admission of hypertensive patients at the University of Benin Teaching Hospital, Nigeria. East Afr Med J. 2007;84:329-335.

45. Ike SO. The pattern of admissions into the medical wards of the University of Nigeria Teaching Hospital, Enugu (2). Niger J Clin Pract. 2008;11:185-192.

46. Walker AR, Walker BF, Dunn MJ, Dunn SE. Causes of admissions of rural African patients to Murchison Hospital, Natal, South Africa. J R Soc Health. 1994;114:33-38.

47. Ojji DB, Alfa J, Ajayi SO, Mamven MH, Falase AO. Pattern of heart failure in Abuja, Nigeria: An echocardiographic study. Cardiovasc J Afr. 2009;20:349-352.

48. Damasceno A, Cotter G, Dzudie A, Sliwa K, Mayosi BM. Heart failure in sub-Saharan Africa: Time for action. J Am Coll Cardiol. 2007;50:1688-1693.

49. Stewart S, Wilkinson D, Hansen C, Vaghela V, Mvungi R, McMurray J, et al. Predominance of heart failure in the Heart of Soweto Study cohort: Emerging challenges for urban African communities. Circulation. 2008;118:2360-2367.

50. Onwuchekwa AC, Onwuchekwa RC, Asekomeh EG. Stroke in young Nigerian adults. J Vasc Nurs. 2009;27:98-102.

51. Mensah GA. Epidemiology of stroke and high blood pressure in Africa. Heart. 2008;94:697-705.

52. Damasceno A, Gomes J, Azevedo A, Carrilho C, Lobo V, Lopes $\mathrm{H}$, et al. An epidemiological study of stroke hospitalizations in Maputo, Mozambique: A high burden of disease in a resource-poor country. Stroke. 2010;41:2463-2469.

53. Amidu N, Owiredu WK, Woode E, Appiah R, Quaye L, Gyasi-Sarpong CK. Sexual dysfunction among Ghanaian men presenting with various medical conditions. Reprod Biol Endocrinol. 2010;8:118.

54. Matekole M, Affram K, Lee SJ, Howie AJ, Michael J, Adu D. Hypertension and end-stage renal failure in tropical Africa. J Hum Hypertens. 1993;7:443-446.

55. Naicker S. End-stage renal disease in sub-Saharan and South Africa. Kidney Intern. 2003;63 Suppl 83:S119-S122.

56. Arodiwe EB, Ike SO, Nwokediuko SC. Case fatality among hypertension-related admissions in Enugu, Nigeria. Niger J Clin Pract. 2009;12:153-156.

57. Unachukwu CN, Agomuoh DI, Alasia DD. Pattern of noncommunicable diseases among medical admissions in Port Harcourt, Nigeria. Niger J Clin Pract. 2008;11:14-17.

58. M'Buyamba-Kabangu JR, Biswika RT, Thijs L, Tshimanga GM, Ngalula FM, Disashi T, et al. In-hospital mortality among black patients admitted for hypertension-related disorders in Mbuji Mayi, Congo. Am J Hypertens. 2009;22:643-648.

59. Kingue S, Dzudie A, Menanga A, Akono M, Ouankou M, Muna W. Nouveau regard sur l'insuffisance cardiaque chronique de l'adulte en Afrique à l'ère de l'échocardiographie Doppler: Expérience du service de médecine de l'Hôpital Général de Yaoundé [A new look at adult chronic heart failure in Africa in the age of Doppler echocardiography: Experience of the medicine department at Yaounde General Hosptital - in French]. Ann Cardiol Angéiol (Paris). 2005; 54:276-283.

60. Ike SO. Prevalence of hypertension and its complications among medical admissions at the University of Nigeria Teaching Hospital, Enugu (Study 2). Nig J Med. 2009;18:68-72.

61. Ogeng'o JA, Olabu BO, Kilonzi JP. Pattern of aortic aneurysms in an African country. J Thorac Cardiovasc Surg. 2010;140:797-800.

62. Brown MJ, Cruickshank JM, Dominiczak AF, MacGregor GA, Poulter NR, Russell GI, et al. Better blood pressure control: How to combine drugs? J Hum Hypertens. 2003;17:81-86.

63. Brown MJ. Hypertension and ethnic group. Br Med J. 2006;332:833-836.

64. Khan JM, Beevers DG. Management of hypertension in ethnic minorities. Heart. 2005;91:1105-1109.

65. Lewin AJ, Lueg MC, Targum S, Cardenas P. A clinical trial evaluating the 24-hour effects of bisoprolol/hydrochlorothiazide $5 \mathrm{mg} / 6.25 \mathrm{mg}$ combination in patients with mild to moderate hypertension. Clin Cardiol. 1993;16:732-736.

66. Zachariah PK, Messerli FH, Mroczek W. Low-dose bisoprolol/hydrochlorothiazide: An option in first-line antihypertensive treatment. Clin Ther. 1993;15:779-787.

67. Papademetriou V, Prisant M, Neutel JM, Weir MR. Efficacy of low-dose combination of bisoprolol/hydrochlorothiazide compared with amlodipine and enalapril in men and women with essential hypertension. Am J Cardiol. 1998; 81:1363-1365.

68. Prisant LM, Neutel JM, Ferdinand K, Papademetriou V, DeQuattro V, Hall WD, et al. Low-dose combination therapy as first-line hypertension treatment for Blacks and Nonblacks. J Natl Med Assoc. 1999;91:40-48.

69. Prisant LM, Weir MR, Papademetriou V, Weber MA, Adegbile IA, Alemayehu D, et al. Low-dose drug combination therapy: An alternative first-line approach to hypertension treatment. Am Heart J. 1995;130:359-366.

70. Neutel JM, Rolf CN, Valentine SN, Li J, Lucas C, Marmorstein BL. Low-dose combination therapy as first line treatment of mild-to-moderate hypertension: The efficacy and safety of bisoprolol/HCTZ versus amlodipine, enalapril, and placebo. Cardiovasc Rev Rep. 1996;17:33-45.

71. Waeber B, Ruilope LM. Amlodipine and valsartan as components of a rational and effective fixed-dose combination. Vasc Health Risk Manag. 2009;5:165-174.

72. Schrader J, Salvetti A, Calvo C, Akpinar E, Keeling L, Weisskopf $\mathrm{M}$, et al. The combination of amlodipine/valsartan 5/160 mg produces less peripheral oedema than amlodipine $10 \mathrm{mg}$ in hypertensive patients not adequately controlled with amlodipine 5 mg. Int J Clin Pract. 2009;63:217-225.

73. Fogari R, Zoppi A, Ferrari I, Mugellini A, Preti P, Derosa G. Effect of valsartan or olmesartan addition to amlodipine on ankle edema in hypertensive patients. Clin Exp Hypertens. 2010;32:245-250.

74. Flack JM, Calhoun DA, Satlin L, Barbier M, Hilkert R, Brunel P. Efficacy and safety of initial combination therapy with amlodipine/valsartan compared with amlodipine monotherapy in Black patients with stage 2 hypertension: The EX-STAND study. J Hum Hypertens. 2009;23:479-488.

75. Destro M, Luckow A, Samson M, Kandra A, Brunel P. Efficacy and safety of amlodipine/valsartan compared with amlodipine monotherapy in patients with stage 2 hypertension: A randomized, double-blind, multicenter study: The EXEFFects study. J Am Soc Hypertens. 2008;2:294-302.

76. Allemann Y, Fraile B, Lambert M, Barbier M, Ferber P, Izzo JL, Jr. Efficacy of the combination of amlodipine and valsartan in patients with hypertension uncontrolled with previous monotherapy: The Exforge in Failure After Single THerapy (EX-FAST) study. J Clin Hypertens. 2010;10:185-194. 
77. Devasenapathy N, Singh K, Prabhakaran D. Conduct of clinical trials in developing countries: A perspective. Curr Opin Cardiol. 2009;24:295-300.

78. Stolarz K, Staessen JA, Kuznetsova T, Tikhonoff V, State D, Babeanu S, et al., on behalf of the European Project on Genes in Hypertension (EPOGH) Investigators. Host and environmental determinants of heart rate and heart rate variability in four European populations. J Hypertens. 2003;21:525-535.

79. Williams B, Lacy PS, Thom SM, Cruickshank K, Stanton A, Collier D, et al. Differential impact of blood pressure-lowering drugs on central aortic pressure and clinical outcomes: Principal results of the Conduit Artery Function Evaluation (CAFE) study. Circulation. 2006;113: 1213-1225

80. Philipp T, Smith TR, Glazer R, Wernsing M, Yen J, Jin J, et al. Two multicenter, 8-week, randomized, double-blind, placebocontrolled, parallel-group studies evaluating the efficacy and tolerability of amlodipine and valsartan in combination and as monotherapy in adult patients with mild to moderate essential hypertension. Clin Ther. 2007;29:563-580.

\section{Supplementary material available online}

\section{Appendix}

